\title{
Gerenciamento do diabetes por profissionais e usuários da Atenção Primária à Saúde
}

| ${ }^{1}$ Priscila Lopes, ${ }^{2}$ José Roque Junges |

Resumo: Diabetes é uma doença que não pode ser curada, mas gerenciada, e seu gerenciamento é visto como uma estratégia para contornar suas consequências desagradáveis em diversas situaçóes de vida. Este trabalho tem por objetivo compreender como ocorre o processo de gerenciamento do diabetes mellitus 2 por profissionais e usuários acometidos por essa condição. Trata-se de uma pesquisa qualitativa, com delineamento observacional e explanatório, que contou com a participação de profissionais de saúde e usuários atendidos por eles, todos da atenção primária à saúde. As informaçóes foram coletadas mediante entrevista semiestruturada e interpretadas usando Análise de Discurso. Para os informantes, os aspectos alimentares são os mais difíceis de lidar. $\mathrm{O}$ discurso dos profissionais aponta para práticas alimentares flexíveis, mas os usuários compreendem as orientaçóes como proibições. A alimentação representa um grande desafio tanto para profissionais quanto para usuários, visto que ambos precisam considerar as práticas de gerenciamento como parte do cuidado.

> Palavras-chave: diabetes mellitus; adesão do paciente; conhecimento em saúde; atitudes; prática.

\author{
1 Saúde Coletiva, Universidade \\ do Vale do Rio dos Sinos. São \\ Leopoldo-RS, Brasil (pri08silva@ \\ gmail.com). \\ ORCID: 0000-0003-4675-0993 \\ 2 Saúde Coletiva, Universidade \\ do Vale do Rio dos Sinos. \\ São Leopoldo-RS, Brasil \\ (roquejunges@hotmail.com). \\ ORCID: 0000-0002-0330-5382
}

Recebido em: 27/08/2019 Aprovado em: 03/03/2020 Revisado em: 13/08/2021 


\section{Introdução}

O diabetes mellitus (DM) é, atualmente, um problema de saúde em âmbito nacional e mundial. Dentre as doenças crônicas não transmissíveis (DCNT), o diabetes mellitus tipo 2 (DM2) representa uma epidemia cujas taxas de incidência e prevalência têm aumentado ano após ano (COSTA et al., 2017; FLOR; CAMPOS, 2017). No Brasil, sua prevalência foi de 7,5\%, com maior acometimento em indivíduos com mais de 65 anos de idade (16,5\%) e do sexo feminino $(8,2 \%)$ (FLOR; CAMPOS, 2017). O DM2 representa quase 5\% da carga de doença no Brasil, com expressiva taxa de agravos (6,1\%) (COSTA et al., 2017). Dados globais apontam que 382 milhóes de pessoas vivem com DM (8,3\%) podendo chegar a 592 milhōes de casos em 2035 (GUARIGUATA et al., 2014). Tal cenário de elevada incidência de DM representa custos econômicos e sociais ao sistema de saúde, ao paciente e seus familiares (TORRES; PEREIRA; ALEXANDRE, 2011; COSTA et al., 2017), pois eleva a busca e uso de serviços de saúde, incluindo internaçóes hospitalares, aumenta a perda de produtividade laboral e doméstica, diminui a funcionalidade e aumenta a incapacidade, além do maior risco para desenvolver outras doenças quando comparados com pessoas sem diabetes (ARRUDA; SCHMIDT; MARCON, 2018), ocasionando mudanças de personalidade, de autoestima e na biografia do sujeito (CANESQUI, 2015).

O DM está entre as doenças que apresentam baixos índices de adesão ao tratamento (BOAS et al., 2011). Arrelias e colaboradores (2015) apontam que 98,3\% dos participantes do estudo apresentaram não adesão ao plano alimentar, $41,9 \%$ à atividade física e $15,8 \%$ ao tratamento medicamentoso.

O adoecimento ocasionado por diabetes é um acontecimento mais complexo do que uma disfunção metabólica, como definida em seu conceito (GUELL, 2011). É preciso compreendê-lo como um fenômeno com expressôes biológicas, psicológicas e sociais (MENDENHALL et al., 2010), visto que a condição crônica impõe mudanças nas atividades diárias, interferindo em todas as dimensóes da vida do sujeito (OROZCO; ALVES, 2017).

De acordo com Barsaglini (2015), Fleischer e Franch (2015), o diabetes é uma doença que não pode ser curada, mas sim gerenciada. Neste sentido, as práticas de gerenciamento dessa condição crônica representam as mais diversas formas de lidar com o DM, nas diversas circunstâncias da vida e do dia a dia, envolvendo o 
modo como o sujeito lida com a doença e tudo o que faz para promover cuidado. Tais práticas buscam articular o controle da doença, simultâneo a um viver mais próximo do que se considera como normal (BARSAGLINI, 2007). O gerenciamento representa também um lidar não somente com os sinais e sintomas da doença, mas uma interação entre profissional e usuário. Envolve o cuidado longitudinal, tornando o gerenciamento mais factível aos serviços da Atenção Primária à Saúde (APS).

$\mathrm{O}$ gerenciamento do $\mathrm{DM}$ não é somente do profissional ou unicamente do usuário, mas uma responsabilidade de ambos. Não existe gerenciamento sem o profissional de saúde e sem o adoecido, pois representa um encontro que alia as duas perspectivas na busca de um cuidado melhor. Em razão desta busca mútua é que o gerenciamento, como tecnologia das práticas de cuidado em saúde, possui relevância. $\mathrm{O}$ gerenciamento compreende uma interação entre a tecnologia dura (uso do glicosímetro), leve-dura (conhecimento) e leve (relação entre profissional e usuário) (MERHY, 1999). A gestáo do DM possibilita uma melhoria no tratamento de casos de DM2, sendo uma alternativa para encontrar bons resultados nos chamados "índices de adesão ao tratamento".

Diferentemente desta perspectiva, estudos internacionais sobre a temática apontam para um gerenciamento, entendido como adesão, o qual visa a aderência às prescriçóes centradas na dieta, exercício e medicamento para o controle da doença (TORRES; PEREIRA; ALEXANDRE, 2011; STROM; EGEDE, 2012; BOELS et al., 2018; GOPALAN et al., 2018). Por vezes é mencionado como sinônimo de autocuidado e como sinônimo de comportamentos (GOPALAN et al., 2018; KARIMY; KOOHESTANI; ARABAN, 2018). Desse modo, a gestão é concebida como comportamentos guiados pelo tripé terapêutico (BECK et al., 2017), o que significa seguir o que foi proposto, representado como adesão ao tratamento e considerado um desafio (KARIMY et al., 2016; STEPHANI; OPOKU; BERAN, 2018). Comumente, algumas pesquisas referem-se à adesão como autogerenciamento, trazendo uma noção limitada e padronizada do gerenciamento (LYNCH et al., 2012; STROM; EGEDE, 2012; GOPALAN et al., 2018; KARIMY et al., 2016).

Todavia, o termo gerenciamento supera a perspectiva biomédica e evita a noção de adesão, termo considerado inadequado por Barsaglini (2011) para a compreensão das doenças crônicas. A adesão traz ideia de rigidez, de práticas inflexíveis nas quais o profissional impóe e o paciente executa (CYRINO, 2009). De modo distinto da 
noção de adesão, o gerenciamento é compreendido por trocas de conhecimentos, por atitudes que promovem práticas em saúde entre profissional de saúde e usuário adoecido, reconhecendo as responsabilidades específicas de cada um, mudando o foco da doença para o doente e do profissional para a relaçáo, possibilitando o cuidado numa perspectiva integral e de corresponsabilidade.

O foco na gestão cotidiana da DM é demonstrado na flexibilidade em relação às práticas alimentares com o intuito de manter a sociabilidade (BARSAGLINI, 2007). Dessa maneira, o gerenciamento do cuidado com a alimentação tornase um exemplo de grande destaque no manejo diário dos serviços de saúde e da vida do adoecido, visto que o alimento não possui apenas uma dimensão biológica com função de nutrir o corpo físico, pois o ato de alimentar-se envolve valores socioculturais (SANTOS; ARAÚJO, 2011) e é permeado por trocas e relaçóes simbólicas (AZEVEDO, 2017).

Desse modo, compreender como ocorre o processo de gerenciamento do diabetes mellitus tipo 2 por profissionais e por usuários acometidos por essa condição crônica, é o objetivo deste estudo.

\section{Caminho metodológico}

A pesquisa teve uma perspectiva qualitativa com delineamento explanatório. A mesma ocorreu no período de 2018/2 em três locais de serviços de saúde de um município da regiáo metropolitana de Porto Alegre-RS. Os dados foram analisados e interpretados a partir da metodologia da Análise de Discurso.

Para essa metodologia analítica, interessam os repertórios interpretativos, que são um conjunto dialógico discursivo retirados da entrevista transcrita (PINHEIRO, 1999). As interações discursivas, presentes nos repertórios, são o foco da análise, pois nelas aparece a realidade das práticas de cuidado em relação ao diabetes, tanto de profissionais quanto de usuários, uma vez que representam as maneiras como as pessoas produzem sentidos através da interação social da linguagem, partindo do fato de que a realidade se apresenta e acontece nesta linguagem, porque dizer é fazer (AUSTIN, 1998). Assim, a construção de subjetividade se faz presente nesse processo, ressignificando a vida na prática discursiva (BRANDÁO, 1994; ORLANDI, 2005; FLICK, 2005). Ou seja, aquilo que é dito apresenta as açóes realizadas, bem como o sentido envolto e condizente com a ação, marcando uma interação discursiva. 
Para esse delineamento investigativo, não seria adequada a análise de conteúdo, porque não interessam os significados isolados que cada um dá ao fenômeno do gerenciamento, mas as interaçóes e o contexto em que se estabelecem na construção da temática em questão.

O estudo foi composto por três locais que realizavam grupo de hipertensão e diabetes (HIPERDIA): duas Estratégias de Saúde de Família (ESF) e uma Unidade Básica de Saúde (UBS). A partir destes grupos, profissionais e usuários foram convidados a participar da pesquisa, sendo três profissionais e três usuários de cada local, totalizando 18 participantes, sendo nove profissionais $(\mathrm{P})$ : três enfermeiros (PE1, PE2, PE3), três médicos (PM1, PM2, PM3), dois odontólogos (PO1, PO2) e um agente comunitário de saúde (PA); nove usuários com DM2 (U) com faixa etária entre 54 e 76 anos e o tempo com a doença desde o diagnóstico entre dois e 20 anos, referidos ao longo do texto como usuárias mulheres (UM1, UM2, UM3, UM4, UM5, UM6) e usuários homens (UH1, UH2, UH3).

Foi realizada uma entrevista semiestruturada com cada participante. Com os profissionais, realizou-se no local de trabalho, e com os usuários, na residência de cada um. $\mathrm{O}$ início da entrevista com o profissional acontecia mediante a solicitação de um caso com DM2 em acompanhamento por ele ou que havia sido acompanhado. Para com os usuários, iniciava-se solicitando que contasse sobre como realizava o cuidado em relação ao diabetes. E para encerrar as entrevistas, utilizou-se o critério de saturação dos dados, as quais foram digitalmente gravadas e posteriormente transcritas.

As provocações indiretas nas entrevistas, mesmo sendo individuais, permitiram ver através da análise de discurso as contraposiçóes e complementaridades, os encontros e desencontros entre os discursos de profissionais e usuários, como no estudo de Almeida, Moutinho e Leite (2014), que também aplicaram entrevistas utilizando o método análise de discurso para interpretação dos dados.

A pesquisa foi aprovada pelo Comitê de Ética em Pesquisa (CEP) da Universidade do Vale do Rio dos Sinos - UNISINOS - sob o parecer de número 2.820.807, conforme a Resolução no 466/12 do Conselho Nacional de Saúde do Brasil.

\section{Resultados e Discussão}

A análise de discurso das entrevistas transcritas deu origem a três interaçóes discursivas, assim denominadas: 1) orientações e proibiçôes sobre a alimentação; 2) adesão e cuidado; 3) gerenciamento. 


\section{Orientaçóes e proibiçóes sobre a alimentaçáo}

As orientaçóes propostas para o cuidado com o diabetes mellitus tipo 2 (DM2) se fundamentam no chamado "tripé", dieta-exercício-medicamento (BECK et al., 2017; BOELS et al., 2018). Isso significa ter uma alimentação equilibrada com quantidade reduzida de determinados alimentos, praticar exercício físico regularmente e o uso devido dos medicamentos; contudo, a ênfase recai sobre a alimentação.

Bom, eu costumo orientar, dar exemplo que o cuidado é basicamente um tripé, não é só remédio, não é só dieta e não é só atividade física. (PM3)

A gente procura ver muito a alimentação deles [...]. (PA)

Olha, primeiro são aquelas orientaçóes básicas de dietas pobres em carboidratos, ai então tu tem que falar aquelas coisas bem básicas: "olha, se tu for comer uma massa, tu tem que comer pouco; se tu comer uma massa tu não come arroz, tu não come batata; se tu come batata, tu não come arroz, tu não come massa, se tu come massa..." daí então as nossas orientaçôes são baseadas na alimentação [...]. (PE1)

De acordo com profissionais e usuários os objetivos da dieta alimentar são os mais difíceis de alcançar, fato corroborado pelo estudo de Cyrino (2009). Comumente, o diabetes representa uma vida de restrições e proibiçóes alimentares. Na perspectiva do profissional, as restriçōes alimentares visam prevenir complicações futuras, mas ao mesmo tempo, para o usuário provocam uma vida de privações.

Eu não tiro arroz e feijão do almoço, [...] só oriento diminuir. (PM1)

Mas a gente nunca tira todo, quem diz que tira todo mente. (UM5)

[...] não proibir, não é a questão de não pode comer, mas sim entender que a proporção tem que ser menor que 50\% de carboidratos [...]. (PM3)

Como é que tu vai ficar sem comer? [...] tudo é proibido comer. (UM6)

Cenoura não podia comer, beterraba não podia comer [...]. (UH2)

Sabe, se a gente for pelo médico, a gente quase não come mais nada. ( $\left.\mathrm{UH}_{3}\right)$

Neste sentido, a recomendação nutricional torna-se um ponto de discrepância entre a prescrição proposta e as açôes efetivas realizadas pelos adoecidos, como demonstrado por Barsaglini e Canesqui (2010) e também por Cyrino (2009). De um lado, temos o discurso dos profissionais com falas sobre redução, não proibição e, de outro, o discurso dos usuários que remetem à percepçáo de proibição alimentar, como foi ilustrado na interação acima (grifo nosso). 
Eu acho que é muito de negociar, que eles possam ter a perspectiva de ter um dia de festa, mas que esse dia náo pode ser todas as semanas porque senão o cuidado acaba se comprometendo. (PM3)

[...] não adianta a gente querer pensar em orientar: "quem sabe troca o teu pão, come um pão integral", eles vão comer aquilo que eles têm ali [...] é muito difícil, primeiro a gente tem que saber bem da realidade daquela pessoa, náo adianta eu querer orientar coisas, ela vai dizer: "tá", mas vai chegar em casa e continuar comendo o que ela tá comendo. (PE2)

O que a gente fala sempre para as pessoas é que elas não precisam estar $100 \%$ do tempo em vigilância para tudo o que se come, mas se no dia a dia a pessoa tem o seu cuidado, tem sua precaução, ela pode de vez em quando dar uma fugidinha, que ela náo vai morrer. (PE1)

Os profissionais apontam para a "negociação" como caminho adequado, procurando conhecer o paciente e sua realidade para poder orientá-lo, propondo uma alternativa para substituir a proibição dos alimentos, com uma reflexão sobre o quê e o quanto seria melhor ingerir. Essa negociação representa uma prática entre profissional e paciente, um diálogo entre ambos para decidir o melhor tratamento aliando as perspectivas do profissional de saúde e do usuário adoecido (CYRINO, 2009), abarcando momentos em que os táo saborosos e prazerosos alimentos poderão ser degustados, não com frequência para não comprometer o controle glicêmico, mas de vez em quando, pois se o cuidar-se for diário, o adoecido pode "dar uma fugidinha".

Entretanto, percebe-se a existência de uma distância entre aquilo que é declarado pelo profissional de saúde e aquilo que é compreendido pelo paciente. Essa distância também foi percebida em outro estudo com doentes crônicos (BARSAGLINI; CANESQUI, 2010). A reprodução verbal dos adoecidos sobre as recomendaçóes alimentares não corresponde ao discurso de flexibilidade e negociação dos profissionais. Observa-se que as relaçóes entre usuários e profissionais são marcadas pelas "proibiçôes". Expressôes como "tudo é proibido comer ou quase não come nada" denotam como são percebidas as restriçoóes alimentares, bem como a dificuldade de alcançar o controle rigoroso proposto nas prescriçóes. Ainda prevalece, como denominado por Barsaglini (2011), a cultura da vigilância, uma observação rigorosa das recomendaçôes, pois o diabetes é uma condição permanente, marcada por privaçôes e restrições, que remete à noção de adesão. Para essa adesão, não há negociação, mas seguimento do prescrito. 


\section{Adesão e Cuidado}

Apesar de proferir um discurso sobre negociação, o conceito de paciente obediente, aquele que adere a tudo o que é proposto e prescrito, ainda é esperado na prática profissional, pois essa negociação está fundamentada na noçáo de adesão ao tratamento.

\footnotetext{
São poucos de fato que aderem [...]. (PM2)

Todos os pacientes tinham uma má adesão [...] hoje, eu posso dizer que $95 \%$ dos pacientes estão adequados, com adesão. (PM1)

Adesão é seguir as recomendaçôes e isso vai ter um resultado na vida da pessoa [...] a não adesão, é justamente porque envolve mudança de hábitos e isso é mais difícil. (PO2)
}

A adesão é um termo que aparece repetidas vezes no discurso dos profissionais. Por vezes, o usuário ainda é classificado como aquele que adere ou não adere, aquele que possui boa ou má adesão, e a promoção do cuidado acaba sendo restrita somente à dieta, exercício e medicamento, pois a adesão é definida como o comportamento de uma pessoa em relação ao fazer uso da medicação, de seguir uma dieta e/ou executar mudanças no estilo de vida a partir de recomendações dialogadas com um provedor de saúde (WHO, 2003). Compreende-se que o próprio termo adesáo limita as práticas de cuidado, pois está focado no biológico e patológico, visando apenas ao controle da doença, enquanto o termo cuidado compreende tudo o que é feito para promover a saúde nas dimensóes do ser biopsicossocial e espiritual inserido num contexto. A noção de aderência ao tratamento traz a ideia de uma relação terapêutica médico-centrada (BARSAGLINI, 2007) e o modo como é definida conduz a uma conotação de rigidez, de práticas inflexíveis nas quais, como afirmou Cyrino (2009), o profissional impóe e o paciente executa, com uma visão reducionista e mecanicista do corpo humano.

Porém, através da análise de discurso, que preconiza ver o contexto da interação (RUEDA, 2003), pode-se compreender que apesar de o conceito de adesão denotar uma obediência sem reflexão e sem sentido, um cumprimento e seguimento de práticas prescritas, o contexto das interaçoos discursivas possui traços do cuidado humanizado. O contexto permite observar que, apesar do uso do termo, as práticas presentes na linguagem, pois "dizer é agir" (AUSTIN, 1998), atentam para o indivíduo e sua situação, demonstrando preocupação com seu bem-estar, apontam para uma reflexão sobre as próprias práticas profissionais, pois, em alguns momentos, 
os profissionais até se colocam no lugar do adoecido, percebendo o quanto suas próprias recomendaçóes são difíceis de seguir, como demonstra o fragmento a seguir:

A adesão pra mim seria seguir as recomendaçôes que a equipe passa, tanto de que são recomendaçôes, que não são fáceis de seguir em função de mudança de hábito de vida, de alimentação [...] acho que tirar é muito difícil, eu penso em mim assim, porque se fosse pra mim fazer assim eu ia achar bem difícil. ( $\left.\mathrm{PO}_{2}\right)$

Enquanto os profissionais utilizam consideravelmente o termo adesão, os usuários em momento algum citam essa palavra ou se autorreferem como alguém que adere ou não, possivelmente por desconhecimento do termo ou por optar pelo uso de outra palavra, como cuidado. Eles usam frequentemente o termo cuidado, sobretudo quando falam de suas práticas para lidar com a doença.

Cuidado traduz o modo como o indivíduo compreende a si e ao mundo (AYRES, 2004) permeado por atitudes que possuem sentido (AYRES, 2009), mas sem se restringir às competências técnicas (AYRES, 2001) e sem desconectar dos contextos sociais e culturais (ZOBOLI, 2007). Por esse motivo, os adoecidos utilizam a palavra cuidado, pois a doença não se desconecta de outras esferas de sua vida.

Não me cuido bem náo, porque quando eu estou com vontade de comer uma fatia de bolo eu como, se eu vou num aniversário eu como. (UH3)

Deveria cuidar, mas a gente tenta fazer. (UH1)

Tem dias que dá uma vontade de comer uma coisa doce assim que tu não tem noção, mas aí eu deixo passar" [...] “eu evito" [...] "eu já não faço pra não comer. (UM5)

E a doutora me xinga, diz que eu não faço, mas eu faço. (UM6)

Os usuários trazem a noção de cuidado, relacionada com o consumo de alimentos. Afirmam não cuidar-se, porque comem aquilo que não poderiam comer, "o alimento proibido". Alguns até se culpam, mesmo que o medicamento seja tomado corretamente e que o exercício seja praticado, mas para eles, o que vale é a alimentação, a dieta foi quebrada e o profissional vai xingar, como demonstrado no discurso acima.

Ficar com minhas filhas, netas [...] meu crochezinho, meu tricô e minha TV [...] eu me sinto bem. (UM5)

Passear, ir na Igreja, é bom [...] todas as quartas-feiras é encontro das senhoras. (UM1)

O discurso dos usuários compreende o cuidado para além daquilo que é proposto pelo profissional, ampliando o modo de lidar com a doença, não restrita ao tripé, dieta, exercício e medicamento, mas agregando outras práticas ao cuidado: 
ficar com os netos, passar um tempo com a família, passear e frequentar grupos da Igreja, considerados como o "seu próprio jeitinho de cuidar-se". Nesse sentido, é interessante notar que o discurso de "não cuidar-se" está relacionado ao fato de não seguir à risca a dieta que o profissional prescreveu e a fala de "práticas de cuidado geral" relaciona-se com tudo o que conseguem fazer para promover cuidado. Tais achados não corroboram o estudo de Pontieri e Bachion (2010), no qual o cuidado acaba sendo restrito somente ao tripé terapêutico sem abarcar outras práticas que também compóem o cuidado e o tratamento em casos de DM2, como percebido no presente estudo.

O cuidado é um conceito mais amplo do que aderência, por isso o termo gerenciamento relaciona-se com cuidado, pois gerenciar não significa aderir.

\section{Gerenciamento}

O gerenciamento representa as formas e estratégias de lidar com a doença e o mundo simultaneamente, constituindo açóes para o controle da doença, articulado ao viver mais próximo do "normal" (BARSAGLINI, 2007). O gerenciamento vai além da doença e se estabelece nas práticas de profissionais e usuários, pois não existe um sem o outro. É uma contínua troca de conhecimentos que exige atitudes de ambos os lados referentes às práticas em saúde. Para o profissional, o gerenciamento se estabelece na sua rotina de trabalho dedicado ao paciente, através de práticas de negociação enfáticas na alimentação; por sua vez, para os usuários o gerenciamento acontece frequentemente na gestão alimentar, inserida no cotidiano da vida.

Páes, esses cacetinhos eu como, eu não deixei de comer, mas moderado [...] e nas festinhas: aí a gente passa do limite. (UM1)

Ah o pão branco eu não consigo largar, um cacetinho de manhã é sagrado. (UM4)

Ah no meu aniversário eu meto o pé na jaca (risos), como salgadinho, como doce [...] meu aniversário é uma vez por ano (risos). (UM5)

Durante a semana, toda semana eu cuido, mas às vezes, que nem assim eu vim em casa, aí que nem hoje a vizinha trouxe um pedaço de bolo, claro que eu comi um pedaço de bolo para experimentar, mas só um dia na semana. (UM6)

Mas eu não abuso muito sabe [...] um refri eu tomo [...] bebe eu não bebo [...] fumar eu fumo bastante. (UH3)

O churrasco de domingo tem que ter, não adianta (risos) [...] e se tu parar total, aí tu fica depressivo aí, tu fica: "ai eu não posso comer nada, não posso". (UH1)

Eu vou, porque lá [nas festinhas] tem salgadinho, essas coisas assim eu como. (UM2) 


\begin{abstract}
A minha neta estava fazendo aniversário na quinta-feira [...] daí meu filho ligou porque ela queria que a vó fosse lá pra cantar os parabéns no bolo [...] e daí eu fui lá, aí eu comi um pedaço de bolo. (UM3)

Então eu peguei o jeito que ela me disse pra mim: "tu pode comer de tudo, mas não tudo". (UH2)
\end{abstract}

O discurso dos usuários mostra que a alimentação é um elemento central da gestão cotidiana, na qual prevalecem os aspectos sociais ao invés dos critérios clínicos e de recomendaçáo médica, quando afirmam não deixar de comer aquilo que se gosta ("o páo cacetinho"), mas comer moderadamente, abrir mão de certos produtos para comer outros ("beber eu não bebo, mas tomo refri"), não deixando de ir nas festinhas porque lá tem alimentos que se "pode" comer, além daqueles que "não pode", não deixando de participar do dia mais importante da neta, aproveitando bem o dia do próprio aniversário, o qual só "acontece uma vez ao ano", não deixando de viver com a família no dia de domingo e se deleitando com aquele "churrasco", comendo de tudo, mas comendo pouco, sem exageros, mas se exagerar e "passar do limite", porque às vezes isso ocorre, basta se cuidar depois. Barsaglini (2011) afirma que, cientes dos exageros, os adoecidos não deixam de compensar com outras estratégias, antes ou depois dessas ocasiôes. Assim, os ajustes e adaptaçóes, conforme as circunstâncias, integram o gerenciamento, viabilizando o sentir-se bem. Tais ajustes buscam aliar a perspectiva do profissional como aquele que entende da doença, e do usuário como aquele que entende de sua vida, pois o gerenciamento não é feito sozinho; é na troca de saberes e práticas que se encontra uma melhor gestão.

Esse manejo diário e em datas especiais articula sensaçóes corporais e prazer da comida (FLEISCHER; FRANCH, 2015), sendo o alimento o elo simbólico das relações (CANESQUI, 2005). O cuidado envolve, primordialmente, a alimentação, o exercício e o medicamento, mas para os usuários, abrange mais coisas, pois perpassa a vida em todas as suas dimensóes. Por isso, "o churrasco de domingo tem que ter", porque isso representa a vida em família, o prazer de viver, a satisfação consigo mesmo e isso tudo é cuidado.

A gente se preocupa um pouco [...] aquela liberdade de querer comer tudo [...]. (UH1)

Tu carrega para o resto da vida aquilo ali, é uma coisa sempre contigo [...] (UM4)

Para mim já faz parte [...] Eu não sou doente [...] doença é câncer, AIDS, doenças que matam, essas aqui (DM, HAS) matam, mas se eu me cuidar não. (UM5) 
Tem que continuar com a herança que ela [mãe] me deu [...] fazer o quê? Saber ou não saber tu vai ter que te cuidar e te controlar [...] porque o que adianta se ela não foge de ti, vai com a gente junto, é uma amiga [...]. (UM3)

O modo de encarar a doença é um importante influenciador das práticas de gerenciamento do cuidado, pois denota uma mudança de consciência em relação à prática alimentar, a partir da descoberta da doença: "não há mais a liberdade para comer tudo"; o comportamento muda - mesmo que náo completamente como esperado pelos profissionais de saúde - as mudanças ocorrem porque "tu carrega a doença pro resto da vida", mas o mais importante é não encará-la como uma doença, mas sim, como algo que "faz parte" da vida, como uma "amiga" que não sai de perto, e sabendo ou não como lidar com ela, você vai ter que viver com ela.

Barsaglini (2011) também reconhece que o jeito de vivenciar e os modos de gerenciar não são únicos nem absolutos. Cada adoecido vai lidar da maneira que para ele faz sentido de se cuidar, como é o caso de duas usuárias da pesquisa. A UM3 afirma que não se importa tanto com a hipertensão arterial sistêmica (HAS), ao ponto que, quando se sente, bem não toma o medicamento de controle da pressão, porém o medicamento do diabetes ela toma "rigorosamente", segundo suas palavras, isso porque sua vivência prévia em relação ao DM2 foi com seu irmão, que morreu devido exacerbação dos sintomas por não se cuidar. UM6 também tem uma vivência familiar, com sua irmã, a qual morreu com vontade de comer, mas não podia por causa do câncer.

A minha irmã tava sempre de dieta, dieta, dieta, e o dia que ela descobriu que tinha câncer ela ficou mal, [...] ela disse que ficou com vontade de comer coisa e não deu. Aí eu às vez digo pra doutora, se me deu uma vontade agora eu vou lá e como, não fico mais com vontade. [...] E mesmo a doutora xingando, eu disse assim: "hoje eu comi". (UM6)

O que aconteceu com a irmã da UM6 a impactou tanto que esta vivência influencia suas práticas de gerenciamento em relação ao DM2, tornando isso visível quando diz: "não fico mais com vontade", fato que ocorre devido aos significados socioculturais que os alimentos possuem atrelados às experiências de vida (BARSAGLINI, 2008) e vivências com um ente querido (PACE; NUNES; OCHOA- VIGO, 2003).

O paciente diabético e hipertenso, ele é bem complexo, porque não envolve as questóes só de vida saudável [...]. (PE3)

[...] às vezes o que eu acho que é saúde para o meu usuário pode ser que para ele não seja

[...] para ele talvez ser saudável é comer o que ele quiser a hora que ele quiser. (PO1) 
O usuário acometido por diabetes não está envolvido somente por "questôes de vida saudável", como afirmado pelo enfermeiro (PE3), envolve outras esferas de sua vida, a própria concepção de "saudável" muda de pessoa para pessoa conforme relatado pela odonto (PO1).

Assim, o gerenciamento da alimentação envolve ajustes nas orientaçóes dietéticas como uma estratégia de controlar a doença sem ser controlado por ela (BARSAGLINI; CANESQUI, 2010) tornando possível um viver com e apesar da doença (NEVES, 2015). Contudo, em sua maioria, os profissionais acabam não assumindo essas práticas como gerenciamento e como parte do cuidado em saúde, mas como um não seguimento das recomendações terapêuticas, como desobediência, pois quando o paciente expressa sua prática de gerenciamento: "comi um bolo, tomei refri" em determinada situação, é tido como desobediente, como aquele que náo adere.

Por sua vez, os usuários se culpam por suas práticas de gerenciamento por considerá-las como algo que não deveriam fazer. Desse modo, percebe-se que profissionais e usuários avaliam o sucesso de um tratamento de forma diferente. Para os profissionais, o aspecto central é o controle da doença, seguindo a prescrição à risca, mantendo rigorosamente sinais e sintomas dentro dos padrôes de normalidade, mesmo que isso possa interferir drasticamente no cotidiano do adoecido, enquanto que para os pacientes o foco é conseguir lidar com sua vida e com a doença, sentindose bem apesar do diabetes, impedindo que esta interfira radicalmente em sua vida, vivendo e comendo como se gosta, mas controlando os sinais e sintomas para não ser controlado pela doença.

Para os profissionais, a importância da alimentação é vista do ponto de vista fisiológico e biológico. Para os adoecidos, o momento da alimentaçáo integra família e amigos, cultivando histórias, sendo o alimento uma fonte de prazer e oportunidade de socialização (PROENÇA, 2010; NEVES, 2015). Assim, o gerenciamento se insere no cuidado, mediando a relação entre profissional e usuário, estabelecendo um diálogo no qual não há predominância de um lado, mas uma interação dos saberes e práticas de ambos. Apesar da aproximação dos conceitos de autocuidado e autogerenciamento, evita-se o emprego desses termos, pois não se trata somente da dimensão individual "auto", mas da dimensão interativa entre profissional e usuário que acontece no gerenciamento e no cuidado. 
Assim, os dados desta pesquisa demonstram que o gerenciamento faz parte do cuidado com intuito de refletir em melhorias no cuidado em saúde, não somente das práticas do usuário, mas também do profissional, pois não existe gerenciamento sem a atuação de ambos.

\section{Considerações finais}

Será a adesão um desafio como apontado pela literatura? Ou será a prática do gerenciamento como parte do cuidado, um desafio para o acompanhamento de casos com diabetes mellitus?

Sendo a alimentação o aspecto mais difícil de controlar, seguir tudo à risca, como denota o termo adesão, é algo impossível segundo os usuários, emergindo então as práticas de gerenciamento como uma estratégia de cuidado, e não como uma desobediência à orientação.

O diabetes, como uma condição crônica, requer um processo de gerenciamento, entendido como interação entre o adoecido e os profissionais de saúde, a fim de que se permita um manejo da doença nas diversas circunstâncias da vida. Por isso, essa noção difere da adesão ao tratamento, que visa apenas ao cumprimento de prescriçôes com preocupação focada no controle da doença, enfatizando os desvios do adoecido, classificado como "aquele que não adere".

O gerenciamento se dá no diálogo entre profissional e usuário para reduzir os agravos de sua condição, além de abrandar a ideia de restrição, de proibição e uma vida sem prazeres que a percepção sobre diabetes traz, propiciando melhorias no cuidado em saúde, sem esquecer o cotidiano da vida.

$\mathrm{O}$ estudo do gerenciamento do DM2 contribui para a visibilidade de um novo olhar por parte dos profissionais da Atenção Primária à Saúde, um olhar mais voltado às dimensóes psicossociais envolvidas no cuidado, trazendo a compreensão da realidade e dos enfrentamentos vividos por pessoas com DM2 no manejo diário de sua condição crônica, apontando o gerenciamento como eixo norteador das práticas de saúde.

Através desta pesquisa, percebe-se o diabetes como algo que estimula a transformação do cuidado em saúde, instigando a necessidade de um olhar, de profissionais e usuários, para além da doença e da adesão ao tratamento. ${ }^{1}$ 


\section{Referências}

ALMEIDA, E. R.; MOUTINHO, C. B.; LEITE, M. T. S. A prática da educação em saúde na percepção dos usuários hipertensos e diabéticos. Saúde em Debate, v. 38, n. 101, p. 328337, abr-jun. 2014. Disponível em: <http://www.scielo.br/pdf/sdeb/v38n101/0103-1104sdeb-38-101-0328.pdf>. Acesso em: 06 ago. 2019.

ARRELIAS, C. C. A. et al. Adesão ao tratamento do diabetes mellitus e variáveis sociodemográficas, clinicas e de controle metabólico. Acta paul. enferm., São Paulo, v. 28, n. 4, p. 315-322, ago. 2015. Disponível em: <http://www.scielo.br/pdf/ape/v28n4/1982-0194ape-28-04-0315.pdf>. Acesso em: 06 ago. 2018.

ARRUDA, G. O.; SCHMIDT, D. B.; MARCON, S. S. Internaçóes por diabetes mellitus e a Estratégia Saúde da Família, Paraná, Brasil, 2000 a 2012. Ciência \& Saúde Coletiva, v. 23, n. 2, p.543-552, mai. 2018. Disponível em: < http://www.scielo.br/pdf/csc/v23n2/1413-8123csc-23-02-0543.pdf>. Acesso em: 06 ago. 2019.

AUSTIN, J. L. Cómo hacer cosas com palavras. Palavras y Acciones. Barcelona: Paidós, 1998.

AYRES, J. R. C. M. Sujeito, intersubjetividade e práticas de saúde. Ciênc. saúde coletiva, Rio de Janeiro, v. 6, n. 1, p. 63-72, 2001. Disponível em: <http://www.scielo.br/pdf/csc/v6n1/7025. pdf>. Acesso em: 28 fev. 2019.

. O cuidado, os modos de ser (do) humano e as práticas de saúde. Saúde soc., São Paulo, v. 13, n. 3, p. 16-29, dez. 2004. Disponível em: <http://www.scielo.br/pdf/sausoc/v13n3/03. pdf>. Acesso em: 28 fev. 2019.

. Cuidado: trabalho e interação nas práticas de saúde. Rio de Janeiro: Cepesc; UERJ/ IMS; Abrasco, 2009. (Clássicos para integralidade em saúde).

AZEVEDO, E. Alimentação, sociedade e cultura: temas contemporâneos. Sociologias, Porto Alegre, v. 19, n. 44, p. 276-307, jan. 2017. Disponível em: <http://www.scielo.br/pdf/soc/ v19n44/1517-4522-soc-19-44-00276.pdf>. Acesso em: 06 ago. 2019.

BARSAGLINI, R. A. “Com açúcar no sangue até o fim”: Um estudo de caso sobre o viver com diabetes. In: CANESQUI, A. M. Olhares socioantropológicos sobre os adoecidos crônicos. 1. ed. São Paulo: HUCITEC, 2007. p. 53-85.

BARSAGLINI, R. A. Análise socioantropológica da vivência do diabetes: um estudo de caso. Interface (Botucatu), Botucatu, v. 12, n. 26, p. 563-577, set. 2008. Disponível em: <http://www. scielo.br/pdf/icse/v12n26/a09.pdf>. Acesso em: 14 maio 2019.

BARSAGLINI, R. A. CANESQUI, A. M. A alimentação e a dieta alimentar no gerenciamento da condição crônica do diabetes. Saúde soc., São Paulo, v. 19, n. 4, p. 919-932, dez. 2010. Disponível em: <http://www.scielo.br/pdf/sausoc/v19n4/18.pdf>. Acesso em: 14 maio 2019. 
BARSAGLINI, R. A. As representaçôes sociais e a experiência com diabetes: um enfoque socioantropológico. 1. ed. Rio de Janeiro: Fiocruz, 2011.

Adoecimentos crônicos, condiçóes crônicas, sofrimentos e fragilidades sociais: algumas reflexóes. In: CANESQUI, A. M. Adoecimentos e sofrimentos de longa duração. 1. ed. São Paulo: Hucitec, 2015. p. 70-103.

BECK, J. et al. 2017 National Standards for Diabetes Self-Management Education and Support. Diabetes Care, v. 40, n. p. 1409-1419. out. 2017. Disponível em: <http://care.diabetesjournals. org/content/diacare/40/10/1409.full.pdf>. Acesso em: 14 maio 2019.

BOAS, L. C. G. et al . Adesão à dieta e ao exercício físico das pessoas com diabetes mellitus. Texto contexto - enferm., Florianópolis, v. 20, n. 2, p. 272-279, jun 2011. Disponível em: <http:// www.scielo.br/pdf/tce/v20n2/a08v20n2.pdf>. Acesso em: 06 ago. 2019.

BOELS, A. M. et al. Effectiveness of diabetes self-management education via a smartphone application in insulin treated type 2 diabetes patients - design of a randomised controlled trial ('TRIGGER study'). BMC endocrine disorders, v. 18, n. 1, Out. 2018. Disponível em: <https:// www.ncbi.nlm.nih.gov/pmc/articles/PMC6196442/pdf/12902_2018_Article_304.pdf>. Acesso em: 14 maio 2018.

BRANDÃO, H. H. N. Introdução à análise do discurso. 3. ed. Campinas: UNICAMP, 1994.

CANESQUI, A. M. Mudanças e permanências da prática alimentar cotidiana de famílias de trabalhadores. In: CANESQUI, Ana Maria; DIEZ-GARCIA, R. W. (org.). Antropologia e nutrição: um diálogo possível. Rio de Janeiro: Fiocruz, 2005, p. 167-210.

CANESQUI, Ana Maria. Adoecimentos e sofrimentos de longa duração. 1. ed. São Paulo: Hucitec, 2015. COSTA, A. F. et al. Carga do diabetes mellitus tipo 2 no Brasil. Cadernos de Saúde Pública, v. 33, n. 2. 2017. Disponível em: < http://www.scielo.br/pdf/csp/v33n2/1678-4464-csp-3302-e00197915.pdf>. Acesso em: 06 ago. 2019.

CYRINO, A. P. Entre a Ciência e a Experiência: Uma Cartografia do Autocuidado no Diabetes. 1. ed. São Paulo: UNESP, 2009.

FLEISCHER, S.; FRANCH, M. Uma dor que não passa: Aportes teórico-metodológicos de uma Antropologia das doenças compridas. Revista de Ciências Sociais Politica e Trabalho, n. 42, p. 13-28, jan./jun. 2015. Disponível em: <http://www.periodicos.ufpb.br/index.php/ politicaetrabalho/issue/view/1659/showToc>. Acesso em: 04 mar. 2019.

FLICK, U. Uma Introdução à Pesquisa Qualitativa. Porto Alegre: Bookman, 2005.

FLOR, L. S.; CAMPOS, M. R. Prevalência de diabetes mellitus e fatores associados na população adulta brasileira: evidências de um inquérito de base populacional. Revista Brasileira de Epidemiologia, v. 20, n. 01, pp. 16-29. jan-mar. 2017. Disponível em: <http://www.scielo.br/ pdf/rbepid/v20n1/1980-5497-rbepid-20-01-00016.pdf>. Acesso em: 06 ago. 2019. 
GOPALAN, A. et al. Exploring how patients understand and assess their diabetes control. BMC Endocr Disord. v. 18, n. 6. nov. 2018. Disponível em: <https://www.ncbi.nlm.nih.gov/ pmc/articles/PMC6219190/pdf/12902_2018_Article_309.pdf>. Acesso em: 14 maio 2019.

GUARIGUATA, L. et al. Global estimates of diabetes prevalence for 2013 and projections for 2035. Diabetes Res Clin Pract., v.103. n. 2, p.137-49, fev. 2014. Disponível em: <https:// www.diabetesresearchclinicalpractice.com/article/S0168-8227(13)00385-9/pdf>. Acesso em: 06 ago. 2019.

GUELL, C. Biosocialities of Turkish Berliners Living with Diabetes. Medical Anthropology Quarterly, v. 25, n. 3, p. 377-394, 2011. Disponível em: <https://www.ncbi.nlm.nih.gov/ pubmed/22007563>. Acesso em: 22 fev. 2019.

KARIMY, M. et al. Determinants of adherence to self-care behavior among women with type 2 diabetes: an explanation based on health belief model. Medical journal of the Islamic Republic of Iran, v. 30, n. 368. Maio 2016. Disponível em: <https://www.ncbi.nlm.nih.gov/pmc/articles/ PMC4972051/pdf/mjiri-30-368.pdf>. Acesso em: 15 maio 2019.

KARIMY, M.; KOOHESTANI, H. R.; ARABAN, M. The association between attitude, self-efficacy, and social support and adherence to diabetes self-care behavior. Diabetology \& metabolic syndrome, v. 10, n. 86, nov. 2018. Disponível em: <https://www.ncbi.nlm.nih.gov/ pmc/articles/PMC6260748/pdf/13098_2018_Article_386.pdf>. Acesso em: 14 maio 2019.

LYNCH, E. B. et al. Concepts of diabetes self-management in Mexican American and African American low-income patients with diabetes. Health Education Research, v. 27, n. 5 , p. 814-824, out. 2012. Disponível em: <https://www.ncbi.nlm.nih.gov/pubmed/22641792>. Acesso em: 15 maio 2019.

MENDENHALL, E. et al. Speaking through Diabetes: Rethinking the Significance of Lay Discourses on Diabetes. Medical Anthropology Quarterly, v. 24, n. 2, p. 220-239, jun. 2010. Disponível em: <https://www.ncbi.nlm.nih.gov/pubmed/20550094>. Acesso em: 22 fev. 2019. MERHY, E. E. O ato de governar as tensôes constitutivas do agir em saúde como desafio permanente de algumas estratégias gerenciais. Ciênc. saúde coletiva, Rio de Janeiro, v. 4, n. 2 , p. 305-314, 1999. Disponível em: <http://www.scielo.br/pdf/csc/v4n2/7114.pdf>. Acesso em: 16 ago. 2019.

NEVES, E. Viver com (e apesar de) a doença: apontamentos sobre a experiência do adoecimento crônico entre diabéticos da Associação de Diabéticos de João Pessoa, Paraíba, Brasil. Revista de Ciências Sociais Politica e Trabalho, n. 42, p. 111-131, jan./jun. 2015. Disponível em: <http:// www.periodicos.ufpb.br/index.php/politicaetrabalho/article/viewFile/22790/14158>. Acesso em: 20 fev. 2019.

ORLANDI, E. P. Análise do Discurso: princípios e procedimentos. 6. ed. Campinas: Pontes Editores, 2005. 
OROZCO, L. B.; ALVES, S. H. S. Diferenças do autocuidado entre pacientes com diabetes mellitus tipo 1 e 2. Psic., Saúde \& Doenças, Lisboa, v. 18, n. 1, p. 234-247, abr. 2017. Disponível em: <http://www.scielo.mec.pt/pdf/psd/v18n1/v18n1a19.pdf>. Acesso em: 15 mar. 2019.

PACE, A. E.; NUNES, P. D.; OCHOA-VIGO, K. O conhecimento dos familiares acerca da problemática do portador de diabetes mellitus. Rev. Latino-Am. Enfermagem, Ribeirão Preto, v.11, n. 3, p. 312-319, jun. 2003. Disponível em: <http://www.scielo.br/pdf/rlae/v11n3/16540. pdf>. Acesso em: 06 mar. 2019.

PINHEIRO, O. G. Entrevista: uma prática discursiva. In: SPINK, M. J. (org.) Práticas discursivas e produção de sentido no cotidiano. São Paulo: Cortez, 1999, p. 183-214.

PONTIERI, F. M.; BACHION, M. M. Crenças de pacientes diabéticos acerca da terapia nutricional e sua influência na adesão ao tratamento. Ciênc. saúde coletiva, Rio de Janeiro, v. 15, n. 1, p. 151-160, jan. 2010. Disponível em: <http://www.scielo.br/pdf/csc/v15n1/a21v15n1.pdf>. Acesso em: 16 ago. 2019.

PROENÇA, R. P. C. Alimentação e globalização: algumas reflexões. Cienc. Cult., São Paulo, v. 62, n. 4, p. 43-47, Out. 2010. Disponível em: <http://cienciaecultura.bvs.br/pdf/cic/v62n4/ a14v62n4.pdf>. Acesso em: 18 fev. 2019.

RUEDA, L. I. El análisis del discurso en las ciencias sociales: variedades, tradiciones y práctica. In: RUEDA, L. I. Análisis del discurso: manual para las ciencias sociales. Barcelona: UOC, 2003.

SANTOS, A. F. L.; ARAUJO, J. W. G. Prática alimentar e diabetes: desafios para a vigilância em saúde. Epidemiol. Serv. Saúde, Brasília, v. 20, n. 2, p. 255-263, jun. 2011. Disponível em: <http://scielo.iec.gov.br/pdf/ess/v20n2/v20n2a14.pdf>. Acesso em: 06 ago. 2019.

STEPHANI, V.; OPOKU, D.; BERAN, D.. Self-management of diabetes in Sub-Saharan Africa: a systematic review. BMC public health, v. 18, n. 1, set. 2018. Disponível em: <https:// www.ncbi.nlm.nih.gov/pmc/articles/PMC6162903/pdf/12889_2018_Article_6050.pdf>. Acesso em: 15 maio 2019.

STROM, J. L.; EGEDE, L. E. The impact of social support on outcomes in adult patients with type 2 diabetes: a systematic review. Curr Diab Rep.v. 12, n. 6, p. 769-781, dez. 2012. Disponível em: <https://www.ncbi.nlm.nih.gov/pmc/articles/PMC3490012/pdf/nihms-406410.pdf>. Acesso em: 14 maio 2019.

TORRES, H. C.; PEREIRA, F. R. L.; ALEXANDRE, L. R. Avaliação das açóes educativas na promoção do autogerenciamento dos cuidados em diabetes mellitus tipo 2. Rev. esc. enferm. USP, São Paulo, v. 45, n. 5, p. 1077-1082, out. 2011. Disponível em: <http://www.scielo.br/pdf/ reeusp/v45n5/v45n5a07.pdf>. Acesso em 14 maio 2019.

WORLD HEALTH ORGANIZATION (WHO). Adherence to long-term therapies: Evidence for action. Geneva, 2003. Disponível em: <http://www.who.int/chp/knowledge/publications/ adherence_report/en/>. Acesso em: 06 fev. 2019. 
ZOBOLI, E. Ética do cuidado: uma reflexão sobre o cuidado da pessoa idosa na perspectiva do encontro interpessoal. Saúde Coletiva, v. 4, n. 17, p. 158-162, set. 2007. Disponível em: <https:// www.redalyc.org/pdf/842/84201706.pdf>. Acesso em: 28 fev. 2019.

\section{Nota}

${ }^{1}$ P. Lopes: redação, revisão do artigo e aprovação final da versão final. J. R. Junges: desenho do estudo, coleta, análise e interpretação dos dados; redação do artigo. 


\section{Abstract}

\section{Management of diabetes by professionals and users of Primary Health Care}

Diabetes is a disease that cannot be cured, but managed, and its management is seen as a strategy to overcome its unpleasant consequences in various life situations. This study aims to understand how the diabetes mellitus 2 management process occurs by professionals and users affected by this condition. This is a qualitative research, with observational and explanatory design, which included the participation of health professionals and users they care for, all from primary health care. Information was collected through semi-structured interviews and interpreted using Discourse Analysis. For informants, food aspects are the most difficult to deal with. The professionals' discourse points to flexible eating practices, but users understand the guidelines as prohibitions. Feeding represents a great challenge for both professionals and users, as both need to consider management practices as part of care.

Keywords: diabetes mellitus; patient's compliance; health knowledge; attitudes; practice. 